Revista de la red interuniversitaria de estudios sobre las literaturas rioplatenses contemporáneas en Francia

16 | 2017

Esnobismos

\title{
El hombre de la literatura
}

\section{Gérard Dessons}

Translator. Christian Galdón

\section{(2) OpenEdition}

\section{Journals}

Electronic version

URL: http://journals.openedition.org/lirico/3582

DOI: $10.4000 /$ lirico.3582

ISSN: 2262-8339

\section{Publisher}

Réseau interuniversitaire d'étude des littératures contemporaines du Río de la Plata

\section{Electronic reference}

Gérard Dessons, «El hombre de la literatura », Cuadernos LIRICO [En línea], 16 | 2017, Puesto en línea el 23 septiembre 2017, consultado el 19 abril 2019. URL : http://journals.openedition.org/lirico/3582 ;

DOI : 10.4000/lirico.3582

This text was automatically generated on 19 April 2019.

\section{(c) (1) () $\Theta$}

Cuadernos LIRICO está distribuido bajo una Licencia Creative Commons Atribución-NoComercial-

SinDerivar 4.0 Internacional. 


\section{El hombre de la literatura}

\section{Gérard Dessons}

Translation : Christian Galdón

En nombre de Cuadernos LIRICO agradecemos el acuerdo del autor para publicar esta traducción. El original en francés fue publicado en 2004 en la plataforma Polart -politique et poétique de l'arty se encuentra disponible en línea $: h t t p: / / p o l a r t n e t . f r e e . f r / p a p i e r s / t e x t e s . p h p$

\section{Argumento}

1 Para el campo de los estudios literarios, la cuestión del hombre únicamente cobra sentido si se toma en la actualidad de su formulación. En este caso, el interrogante dirigido a la literatura por las ciencias humanas -y más generalmente al arte-, sobre un nuevo modelo para pensar una antropología.

2 El contexto de esta interrogante provoca que los especialistas de la literatura no puedan evitar una disposición de respuestas implicadas por las prácticas de cada disciplina, ya sean estas herederas de la tradición literaria o tributarias de la estética ; al menos para no entrar en un círculo vicioso que transformaría en respuesta el simple retorno de la pregunta al remitente.

3 El modelo del sujeto trascendental conducía a la antropología humanista a pensar el hombre y la literatura a partir de una doble relación de exterioridad; la instrumentalización del lenguaje constituía a la literatura en suplemento estético. La epistemología estructuralista, por el contrario, se negó a hacer esto. Pero esa "negación" es una motivación, no una actividad crítica, como bien ha quedado expuesto en las aplicaciones cientificistas de modelos lingüísticos a los textos literarios. Esto explica, entre la represión y el exilio, los avatares del "retorno del sujeto", cuyos efectos tardíos se pueden apreciar actualmente con la restauración de la noción de autor, sobre todo cuando ésta toma la forma de la negación.

4 La cuestión del hombre puede tener sentido específico para el campo literario únicamente en la medida en que nos conduce a considerar la literatura como una actividad epistemológica, definiendo infinita e históricamente las condiciones de una 
antropología del lenguaje. En este marco, intentaré formular esta cuestión examinando cómo la literatura vuelve indisociables el pensamiento del individuo y el de la sociedad.

\section{Introducción} examinado el hombre del arte, en el sentido que el arte es un englobante, donde también se incluye la literatura. Si la apuesta por una epistemología de las ciencias humanas toma en cuenta estas dos entidades en un mismo movimiento, el punto de vista del hombre de la literatura es específico.

Por un lado, sobre el plano de una estrategia crítica, el hombre de la literatura está actualmente menos asfixiado por el hombre de la estética que el hombre del arte. Y digo bien "menos". que es igual, al interpretante de toda experiencia humana. Su teorización se inscribe en la óptica de una poética del arte, que sitúa el valor, tanto de la literatura como del arte en general, en la relación establecida con el lenguaje. En este sentido, el pensamiento de un hombre de la literatura podrá proponer un modelo para pensar el hombre del arte. señalar algunos puntos sensibles en la relación crítica entre arte (literatura) y ciencias humanas.

El arte, lo definamos como un lugar, un campo, una cuestión, un problema, no es una esencia, sino un conjunto de discursos, que pueden tener, o no, que ver con la estética. En todo caso, el arte es un lugar particular, donde se ponen a prueba las especificidades disciplinarias de las ciencias humanas. Por ejemplo, porque ellas solo dan cuenta del arte a riesgo de su banalización en el conjunto de los objeto del mundo.

10 El arte y la literatura, tienen esto de particular, ponen en tela de juicio, por su acercamiento a las obras -y, más generalmente, a la obra-, las posiciones consolidadas del individuo y de la sociedad, que son, en tanto que categorías antropológicas, enclaves teóricos y de poder. Lo veremos a propósito de la sociología, donde algunos de sus representantes reconocen que el arte como aproximación a objetos empíricos dificulta la distinción entre "régimen de singularidad" y "régimen de comunidad", cuya demarcación funda la sociología -y no solamente la sociología sino también la psicología, ya sea una psicología de la persona como una psicología social.

11 Esta dificultad hace precisamente del arte un lugar propicio para pensar un hombre donde las nociones de individuo y de sociedad, aunque distintas en el orden conceptual, sean inseparables en un movimiento de conceptualización donde la literatura sea a la vez el objeto y el proceso. En un mismo movimiento, problematizar y pensar el individuo y la sociedad. No en un après-coup, donde la psicología y la sociología converjan para definir el hombre como un ser social, como un individuo que no puede ser determinado más que a partir de su dimensión social. En esta perspectiva, el hombre es pensable bajo el mismo régimen que el de la hormiga o del lobo, lo que acaba por hacer de la sociedad un predicado del individuo. 


\section{Valor -los dos principios-}

12 Ante una obra de arte las ciencias humanas muestran un cierto grado de desorientación. Esta es la lúcida constatación que hace Nathalie Heinich en su libro Ce qui l'art fait à la sociologie (Minuit, 1998) : no hay palabra sociológica que de cuenta de una especificidad artística. Bueno, en realidad sí. Hay una especificidad del arte para la sociología, la de una crítica de la sociología : "El terreno del arte es el lugar por excelencia donde se afirman los valores contra los cuales está constituida la sociología" (p. 7). Aunque esto lo podríamos decir de las ciencias humanas en general, cuyo régimen de racionalidad, cuando se intenta aplicar a la cuestión del arte, se presenta como inadecuado.

13 Heinich lo ve bien, es necesario pensar la relación del arte y -aquí- de la sociología en términos de valor(es). Sé bien que la cuestión del valor es uno de los lugares comunes del pensamiento contemporáneo. Pero hay dos razones para no ignorar los lugares comunes : la primera, para tratar de evitarlos, esto educa los reflejos. La segunda : para aprender a ponerse del lado de los que los emiten, esto desarrolla el sentido crítico.

14 Los valores en los que el arte y la literatura resultan determinantes son, a la vez, valores éticos, políticos y epistemológicos. Ellos nos conducen a pensar las condiciones mismas del pensar. Ellos subrayan una epistemología de las categorías, no de su uso, sino de su organización en un sistema. No se trata de preguntarse, como Macherey, "en qué" piensa la literatura, ni siquiera cómo piensa, sino cómo ella hace pensar, y más precisamente, cómo ella hace pensar al pensar-mismo. El reciente libro de Vicent Jouve, Poétique des valeurs (PUF, 2001), muestra toda la amplitud del malentendido, pues propone limitarse "a los valores revindicados por el texto [La condition humaine]" (p. 11). Jouve evoca, por ejemplo, la "visión del bien y del mal" (p. 15). Estos valores no son los de la literatura. Son los de los autores.

15 En el marco de esta cuestión de la literatura como epistemología, volvamos al libro de $\mathrm{N}$. Heinich. Allí se muestra que toda la cuestión de las relaciones del arte con las ciencias humanas reside tanto en la crítica de los sistemas que intentan pensar lo antropológico, como en la crítica de la organización de las categorías que estructuran su epistemología disciplinaria.

16 De este modo, el lugar donde la sociología tropieza es, evidentemente, en la articulación de la cuestión artística con la polaridad antropológica, que es, específicamente, la suya : a la noción de arte "son espontáneamente asociados estos dos valores antinómicos de la postura sociológica : la exigencia de singularidad y la exigencia de universalidad" (p. 8).

17 El problema es que la sociología propone volver a cuestionar la relación de la sociología con el arte a partir de una concepción del arte que incluye a la sociología en su propia disciplinaridad, así como en una parte importante de su epistemología. N. Heinich lo formula en una serie de oposiciones : "Lo individual confrontado a lo colectivo, el sujeto a lo social, la interioridad a la exterioridad, lo innato a lo adquirido, el don natural a los aprendizajes culturales" (p. 7). Reconocemos dos paradigmas presentes : la naturaleza y la cultura. De un lado : lo individual, el sujeto, la interioridad, lo innato, el don natural. Del otro : lo colectivo, lo social, la exterioridad, lo adquirido, los aprendizajes culturales. Y esto con paradigmas "aproximativos", que vuelven sustituibles nociones que, desde otras perspectivas, son opuestas : lo colectivo, lo general, lo universal (p. 17). 
18 Hoy en día se trata de saber si la reflexión puede sostenerse o no en una aporía de esa índole; si esta puede mantener esos dos paradigmas, o lo que es igual, si el razonamiento de la relación arte/sociología implica el desplazamiento de las categorías que sirven para formular el problema. En resumidas cuentas, saber si la categorización del problema es o no la categorización de la solución, es decir, si el problema se considera o no como parte de la categorización.

\section{La manera}

19 Por un lado, está esa realidad que las ciencias humanas están descubriendo : que el arte es una epistemología crítica. Esto lo separa completamente del punto de vista de la estética. Cabe señalar que, históricamente, la estética es una poética abortada, como lo muestra principalmente la preeminencia acordada a las artes poéticas en la Poética de Aristóteles. (Racine criticaba a los comentadores que vinculaban las obras a una serie de reglas normativas, y revindicaba, por su parte, una lectura de autor: "Que se ahorren el cansancio de aclarar las dificultades de la poética de Aristóteles : que se reserven el placer de llorar y estar conmovidos"). La estética pudo construirse como "ciencia del conocimiento sensible" solo cuando abandonó el punto de vista del arte. Este es el caso de Baumgarten y de Kant. De ahí que las nociones de obra de arte y de objeto estético sean, desde esta perspectiva, heterogéneas, incompatibles.

20 Por otro lado, encontramos la formulación del problema epistemológico. Un problema que es importante -aquí, la oposición entre individuo y sociedad-, y que reescribe la historia de la crítica en una dialéctica infinita entre el "régimen de singularidad" (ética de la rareza, privilegio acordado al sujeto, a lo particular, a lo individual, a lo personal, a lo privado, a la unicidad, a la autenticidad, [p. 11]), y el "régimen de comunidad" (importancia de la cultura, de la época, del siglo, del "campo" [p. 15]). Y es este ping-pong crítico (Nathalie Heinich habla de "combate ritual" [p. 16]) que el arte, en tanto que epistemología critica, daría precisamente a conocer.

21 En realidad, no se trata de tener en cuenta lo que ha pasado antes de la invención de la sociología, antes de la invención de las ciencias humanas, o antes de la invención de la estética (existen otras razones). Hace ya tiempo, efectivamente, que el arte es el terreno de una reflexión sobre una forma particular de individuación. Tampoco se trata de hacer el trabajo de historiador de estas cuestiones, ya que esto exigiría situar de nuevo los hechos en su contexto. Pretendo, simplemente, evocar dos problemas que guardan relación con la noción de manera.

22 El primero concierne a la identificación y a la responsabilidad de una manera. Se cuenta la historia de un retrato de León X hecho por Rafael y Giulio Romano, y copiado por Andrea del Sarto. La copia estaba tan bien hecha, que cuando se la presentaron a Giulio Romano, fue engañado y creyó encontrarse frente al original. Solo cuando le mostraron, en el anverso del cuadro, una marca que identificaba la copia, se convenció de su inautenticidad. Lo que hace de esta historia -verdadera o no- algo que va más allá de una banal alegoría del saber-hacer artístico, es el hecho que Giulio Romano había identificado su mano, en el sentido propio del término : “Es que no reconozco mi Obra, ni veo los pincelazos que yo mismo he dado?". El verbo "reconocer" se presenta aquí como el indicio de un problema : el de la identidad artística. La manera es una mano que pasa de mano en mano, y que continua siendo auténtica. La identificación de las obras, a partir 
del intuicionismo de los "conocedores" clásicos, o, al final del siglo XIX, del procedimiento científico de un Morelli, dejará claro el desafío acordado a la teorización de una categoría de la subjetivación, que Freud llamará una "personalidad artística" basándose precisamente en los trabajos de Morelli, uno de los motores de su teorización del inconsciente-, principalmente a partir de la distinción entre "detalles estéticos", y "detalles in-estéticos" reveladores de un "inconsciente" artístico.

El segundo problema ligado a la manera ha consistido en pensar conjuntamente la individualidad de las prácticas y su devenir colectivo. Este es el caso, tanto de los moralistas como de los especialistas del arte y de la literatura. Diderot, en su ensayo sobre la manera, se metió en un atolladero, pues no logró marcar la diferencia entre la manera personal, la manera de la obra, y la manera en la forma : el manierismo. Lo que lo llevó a este tipo de afirmaciones: "La manera es en las artes lo que la corrupción de las costumbres es en un pueblo". He dicho que Diderot se metió en un "atolladero". No lo digo en un sentido negativo. Al contrario. Diderot dejó en suspenso un problema que no quiso resolver con el dualismo de la manera individual y de la manera de una época. Un tercer término impedía este cierre : la idea de una manera de la obra, esbozada en los Salones. Así las cosas, es precipitado decir, como lo hace Heinich, que "en materia artística, la problemática de la singularidad es esencialmente una característica del arte moderno, aparecida con la imposición progresiva, a partir del segundo tercio del siglo XIX, del "régimen vocacional", o lo que es igual, de una definición de la actividad que, sucediendo al régimen artesanal y al régimen profesional, reposa sobre la valorización de lo singular" (p. 27).

24 Si nos situamos en una perspectiva que tome en cuenta el punto de vista de una historia de las concepciones artísticas, y permaneciendo en el marco europeo, la singularidad como problemática acompaña al arte al menos desde el siglo XVI. Aquí no se trata de dar una lección a nadie, sino de subrayar que una operación historicista puede tapar las historicidades. En particular las de una problemática.

\section{Unicidad-singularidad-originalidad}

La crítica es estratégica. Opera a través de elecciones que califica de necesidades. Esta es su libertad de acción, pero también el reto de su lucidez.

26 El pensamiento de un hombre especifico del arte (y de la literatura) debe, en primer lugar, deshacerse del pensamiento de la unicidad, que implica una ética de la singularidad y una estética de la originalidad. Frente a la generalización "sociológica", la particularización del objeto artístico "cualifica, aumentando el valor del objeto al insistir en su unicidad, su originalidad, su irreductibilidad a categorías" (p. 46). Estamos ante una doxa y una ideología, la del individualismo; esta conlleva una ética y una política. La crítica desde el punto de vista de la unicidad funciona como un mecanismo para desplazar la polaridad que se establece entre el individuo y la sociedad.

27 De hecho, la unicidad tiene una historia, una historia que desemboca en el libro de Max Stirner, L'Unique et sa propriété (1844) : "Yo soy propietario de mi poder, y lo Soy cuando Me reconozco como Único. [...] Si fundo Mi causa en Mí, en lo Único, ella reposa entonces sobre su creador mortal y perecedero, creador que se consume él mismo, y puedo decir : "No he fundado Mi causa sobre la nada" (L'Unique et sa propriété, L'Âge d'Homme, 1972, p. 397). 
28 El pensamiento de lo único reposa en una ética y una política del individualismo que lleva al extremo el impulso hegeliano de cultivar el antagonismo para poder sobrepasarlo: "Nuestra debilidad no reside en el hecho de estar en oposición con otros, sino en que no lo estamos completamente, en que no estamos separados de ellos, buscamos una comunidad, un vínculo, una única fe, un único Dios, una idea única, un único sombrero para todos... Pero la última y más decisiva oposición, la del único contra los únicos, sobrepasa en el fondo aquello que llamamos oposición... ; como único, tú no tienes nada en común con un otro, por lo tanto tampoco hay ni separación ni hostilidad; no buscas tu derecho contra él ante un tercero... La oposición desaparece en la perfecta separación o unicidad" (L'Unique et sa propriété et autres écrits, L'Âge d'Homme, 2012, p. 254).

29 El pensamiento del individuo como único no es una ética de la diferencia (como lo piensa Michel Servière en Le sujet de l'art: "El sujeto del arte, o si se quiere el individuo, el indiscernible, el no-como-un-otro, el no-gregario, el Diferente, el que marca y crea la diferencia y la señala" [p. 25]). Stirner disuelve las diferencias en Únicos, que son entidades autónomas, no relativas. Contra el Estado ( = religión), es necesario promover la asociación (Verein), que aumenta mi poder gracias a una entente con los otros. El pensamiento de la diferencia es un pensamiento de lo relativo, y políticamente, de lo relacional a través de lo relativo. Esta es la razón por la cual hay una cultura de la diferencia que representa, antropológicamente, lo mejor y lo peor : sobre el plano de lo ético (la cuestión del otro), y sobre el plano político (la cuestión del extranjero).

30 El pensamiento de la Unicidad, que incluye la lógica de la diferencia, acaba por sobrepasarla. Después de haber obtenido, gracias a la diferencia, su estatuto de único, el sujeto se autoproclama Dios de su propio reino : "El hombre únicamente ha matado a Dios para devenir ahora... « el único Dios en los cielos »" (p. 207). "Lo divino es la causa de Dios, lo humano es la causa del "hombre". Mi causa no es ni lo divino ni lo humano, ni lo Verdadero, ni lo Bueno, ni lo Justo, ni lo Libre, sino únicamente lo Mío ; no se trata de una causa general, sino... Única, como yo Soy único. / Para Mí, no hay nada más allá de Mí mismo !" (“J’ai fondé ma cause sur rien”, p. 81)

31 No hay pensamiento de lo político posible en esta lógica, o cuanto menos, si existe, es pobre (asociación vs estado) y descansa únicamente en la voluntad de lo único, que puede adherirse o si lo prefiere, distanciarse. El individualismo fanático se somete a lo político, pero no se compromete como la haría en el pensamiento de un Estado, en donde se cuenta con derechos y deberes.

\section{Lenguaje}

32 El reconocimiento por parte de la sociología de la oposición entre los dos "regímenes" (de singularidad y de comunidad) desemboca en un bloqueo de la situación, que lo lleva a la parálisis. Simplemente, la sociología decide buscar en otra parte : en la descripción de los discursos de los "actores" del arte.

33 La operación consiste en desviar las posiciones críticas reduccionistas (lo particular desplazado a lo general de la sociedad) hacia los discursos que representan el punto de vista singularizante. Estamos ante un pasaje copernicano del realismo al nominalismo, pasaje destapado por la sociología (después de Norbert Elias [La Société des individus] o Jules Monnerot [Les Faits sociaux ne sont pas des choses]) : "la singularidad en arte no es una propiedad objetiva de los objetos [...] sino un valor proyectado sobre estos mismos 
objetos, el resultante de una operación de valorización" (p. 26-27). Estamos ante un desplazamiento que ha sido influenciado explícitamente por la etno-metodología (p. 31). Una "sociología de lo real" (p. 29) se transforma en "sociología de las representaciones" (p. 29) : "El régimen de singularidad depende evidentemente de operaciones colectivas, al mismo tiempo que desvaloriza todo lo perteneciente a lo común" (p. 28). En arte, una sociología de las obras cede su lugar a una sociología de los discursos.

El problema en este caso reside en el hecho de que esta sociología de los discursos no es una poética del arte. En el sentido en que esta trabaja en des-especificar el arte como problemática, es decir, precisamente, como discursividad. Así lo podemos ver en el ejemplo de "la muerte prematura del gran creador", una de las representaciones del régimen de singularidad, que de acuerdo a $\mathrm{N}$. Heinich "se declina de manera similar a propósito de Mozart, de Van Gogh, de Rimbaud o de Jean Vigo" (p. 28). Este paradigma de la muerte prematura del gran creador es vinculado con "la constitución de una comunidad de admiración en el duelo del gran singular", el cual, dice N. Heinich, "cumple funciones análogas en el caso de Van Gogh y de Lady Di” (p. 28). El análisis de los discursos, crítico del esencialismo de los universales, está sobredeterminado por un historicismo de las categorías que erige a la analogía en operador de racionalidad, volviendo imposible todo pensamiento de la historicidad del arte vinculado al lenguaje.

A partir del momento en que aceptamos que la oposición subjetividad vs universalidad es una propiedad "lógicamente contradictoria" (p. 46), lo estamos analizando desde la oposición lógica de lo particular y lo general. O de lo singular y de lo general ("incremento de singularidad" vs "incremento de generalidad"). Pero la subjetividad y la universalidad son dos categorías problemáticas y heterogéneas que implican otras polaridades : subjetividad/objetividad, universal/particular (en este caso, lo particular como sinónimo de lo general, que a su vez cambiaría el sentido de lo particular).

\section{Literatura-lenguaje}

36 El hombre de la literatura es antes que nada el hombre del lenguaje. Es decir que el problema de su individuación y de su socialización es un problema de teoría del lenguaje. Pero esta caracterización es una constatación, no una definición.

37 En una perspectiva de definición, tenemos que precisar que el hombre de la literatura, lo que hay que llamar el hombre de la literatura, no es, claro está, una esencia, sino el pensamiento crítico de la relación del hombre con el lenguaje, de su implicación recíproca. Es la intuición de Mallarmé al hablar de "poema crítico". Apuntaba así a una antropología histórica -“Ante la agresión, contestaré que los contemporáneos (el subrayado es mío) no saben leer"-, donde la cuestión del hombre se define en la actividad de lectura. El propósito de Mallarmé afirma el alcance crítico de la literatura en lo más íntimo del hombre : a través de lo cual éste accede a la significación, la suya y la del mundo : la lectura.

38 El hombre y el lenguaje están, gracias a la literatura, recíprocamente implicados. Si los separamos, si dejamos de un lado el hombre y del otro el lenguaje, entonces el lenguaje se encuentra instrumentalizado, y la literatura, estetizada. Este es el esquema de una teoría de la comunicación como teoría de la información. "El lenguaje asocia tres elementos : un Yo, un Tú, un Él o cosa -Alguien habla a alguien de algo" (Valery, Cahiers I, p. 403). Vemos que la definición es exterior : cuestiona las personas empíricas, lo que Benveniste llama 
antónimos: yo, tú, él. Una intersubjetividad queda implicada ahí, pero a través del empirismo de una comunicación, no a través del lenguaje en su funcionamiento mismo, que trabaja a partir del yo y del tú. En términos de ética, estamos ante una moral de la buena intención (volveré sobre este punto.) llevó a pensar al hombre y a la literatura a partir de una doble relación de exterioridad, la de la pareja formada por el hombre y la obra. Esta instrumentalización del lenguaje constituyó a la literatura en un suplemento estético.

40 En la presentación decía que la epistemología estructuralista rechazó este esquema, con un único inconveniente, el de no haber pensado en otro. Ella operó por exclusión, trabajando sobre las representaciones: serie de posiciones (Foucault), el rizoma (Deleuze). Exclusión del sentido, del sujeto, del hombre. Esta exclusión, al tomar el valor de una censura, provocó una represión. De ahí el famoso "retorno del sujeto". Un sujeto que no ha cambiado mucho, simplemente ha envejecido un poco, aunque se mantiene todavía en forma. Un sujeto que es, al mismo tiempo, el locutor, el enunciador, el autor, el proveedor de lo ético, de lo vivido, de lo biográfico (cf. J.-L. Steinmetz, LautreamontDucasse), de lo viviente, de la autenticidad, del sentido (contra la muerte y el absurdo del inmanentismo de las estructuras). A decir verdad, ya no lo esperábamos, pero en el fondo nos alegramos de su regreso : su vuelta rejuvenece a todo el mundo.

41 El esquema es claro: el hombre es definido exteriormente en relación a un lenguaje concebido como una herramienta (un medium, un intermediario), la literatura encuentra su lugar en este dispositivo como suplemento estético, donde el lenguaje pasa del estatuto de instrumento al de material, lo que desemboca en el mismo funcionalismo. Simplemente, el poeta tiene esto de particular : en tanto que utilizador, es también un creador.

42 Hay, sin embargo, en la ficción del hombre ordinario contrapuesto al autor, una intuición : la idea de que el primero utiliza el lenguaje sin resto, es decir, sin consecuencias para su integridad individual (la acción eventual sobre él de su lenguaje no es la de un lenguaje que se define por su actividad, sino la de su uso instrumental, como se ve en la psicología, en la pragmática) ; mientras que el segundo, al mismo tiempo que utiliza el lenguaje, está modificando algo de él. Me estoy refiriendo aquí a las posiciones que construyen al menos una problemática del autor : su distinción, particularmente, con el individuo empírico : las dos morales de Baudelaire ; el Contra Saint-Beuve de Proust.

\section{Utopía}

43 El hombre de la literatura es una utopía, si la literatura es ella misma una utopía. No se trata aquí de una atopía, de algo que no tiene un lugar, sino de algo que aun no ha tenido lugar (cf. H. Meschonnic).

$44 \mathrm{Y}$ es ese aun lo que importa. Trae consigo la historicidad y el valor que vuelven indisociables el pensamiento del individuo y el de la sociedad. El hecho de pensar la literatura a través de la utopía y la utopía a través de la literatura, implica que ese aun no sea una categoría del tiempo cronológico, es decir, que no sea un pensamiento historicista del lugar.

45 Este aun no es un pensamiento del porvenir, del por-venir. No depende de un proyecto. La literatura como utopía del hombre no es una visión utópica, o una construcción profética. Su futuro esta en su presente. Y esto, fuera de toda retórica contractual de una ficción que 
asignaría un valor futuro a un presente de narración. Este presente es del tiempo lingüístico, no del tiempo poético. El tiempo poético no es un presente ontológico, sino el de la empiricidad misma del lenguaje. Se trata efectivamente del presente, no de la presencia.

46 La literatura es, de este modo, lo que en el lenguaje hace de la utopía la ética del valor, su historicidad como informe de invención de un lenguaje, de un sujeto y de una sociedad. Pero, insisto, no mañana sino en este mismo momento. El futuro del hombre es el hombre inventándose precisamente en aquello que no ve que se inventa. Razón por la cual a este hombre, a menudo, lo encontramos del lado del ruido, del parásito, de la broma, de la locura.

47 De ahí que la lectura y la critica estén contenidas en la obra. Positivas o negativas, estas son una respuesta a la obra como interrogante. Es la instauración de un diálogo donde, tal y como insiste una pragmática de los discursos, el interrogado puede, si lo quiere, no responder, pero no puede evitar ser interrogado. Su silencio es una no-respuesta. Una respuesta, al fin y al cabo.

48 El hombre del arte, y el de la literatura, tienen categorías -lexicales- que les son propias. No digo que sean específicas, pero todo el trabajo de teorización consiste en reconocerlas como tales, así como en elevar ciertas nociones al grado de conceptos. Una de las más importantes, en mi opinión, es la de público. Tanto la sociología como la política cuentan con las masas, la multitud. El público es un término especializado, éste implica al arte. Es un singular colectivo, como la multitud, pero se distingue radicalmente en la medida que la multitud es una masa de individuos que se desindividualizan (instinto gregario). El público, por el contrario, es una colectividad que está formada por individuos que no pierden su individualidad, por mucho que ésta se encuentre desplazada. Ellos pertenecen a la obra que los constituye en entidades individuales y colectivas al mismo tiempo. (Artaud). Es a lo que se refiere Valery cuando habla de las obras que crean su público. Y Mallarmé cuando se refiere a los contemporáneos que no saben leer.

Una teoría del lector como publico evita el subjetivismo de la simpatía, de la identificación. El público es el nombre del otro en el arte.

50 La relación con el hombre y con la literatura es entonces doblemente definitoria. Hay literatura cuando una teoría del hombre -y de la sociedad- está en juego en el decir mismo de la obra, y no en lo dicho de ese decir, que, él, abre hacia hermenéuticas y al racionalismo de las interpretaciones. Esto implica que los comentarios sean sobre un hacer del decir y no sobre un dicho del decir.

\section{AUTHORS}

\section{GÉRARD DESSONS}

Université Paris 8 